\title{
Susceptibilidad antimicrobiana, serotipos capsulares y relación clonal entre cepas invasoras de Streptococcus pneumoniae aisladas de pacientes adultos de la Región del Bío-Bío, Chile. Período 2005-2006
}

\author{
Cristian Aguilera R., Gerardo González R., Helia Bello T., Sergio Mella M., \\ Rodrigo Blamey D. *, Henriette Chabouty G., Juan C. Hormazábal O., Aurora Maldonado B., \\ Bianca Rojas U., Mabel Seoane M. y Mariana Domínguez Y.
}

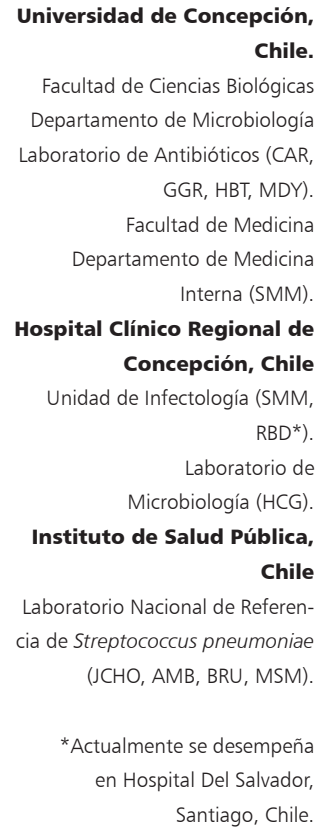

Trabajo financiado por Proyecto DIUC 205.085.029-1.0

Recibido: 27 de julio de 2009 Aceptado: 29 de julio de 2010

Correspondencia a: Mariana Domínguez Yévenes mdomingu@udec.c

\section{Introducción}

S treptococcus pneumoniae, patógeno extracelular clásico, mantiene un papel preponderante como agente etiológico de infecciones menores o no invasoras (otitis media aguda, sinusitis aguda) e infecciones invasoras (neumonía, meningitis bacteriana aguda, bacteriemia $y$, menos frecuentemente, artritis o peritonitis $)^{1}$.

Las infecciones invasoras por $S$. pneumoniae constituyen un serio problema de salud pública en el ámbito mundial y, particularmente, en países en desarrollo, debido a su elevada mortalidad ${ }^{2}$. El compromiso del torrente circulatorio por esta bacteria, particularmente en el contexto de una neumonía, podría agravar el pronóstico ${ }^{3}$. La habilidad de S. pneumoniae para causar enfermedad está directamente relacionada con la presencia de una cápsula polisacárida que se encuentra rodeando la pared bacteriana. Los polisacáridos capsulares son de naturaleza química variada y actúan como antígenos específicos; los distintos serotipos se comportan de manera diferente en cuanto a su capacidad antigénica, virulencia y propiedad colonizadora ${ }^{4}$.
Otro factor que explica la importancia que ha adquirido este patógeno y que ha complicado el manejo de las infecciones neumocóccicas, es el incremento de la resistencia, inicialmente a penicilina y posteriormente a cefalosporinas y otras familias de antimicrobianos ${ }^{5}$.

Estudios de epidemiología molecular han evidenciado que el aumento de la resistencia a penicilina en S. pneumoniae sería el resultado de dos fenómenos concomitantes, la importación de clones internacionales que poseerían un carácter epidémico y atributos especiales de virulencia y múltiples eventos de transferencia horizontal de resistencia a cepas susceptibles, que ocurren de manera independiente y localizada. Se ha logrado determinar, mediante estudios de tipificación molecular en muchas regiones del mundo, un número importante de clones de $S$. pneumoniae resistentes a antimicrobianos que han alcanzado una importante diseminación geográfica ${ }^{6}$.

En nuestro medio destaca la ausencia de estudios prospectivos sobre infección neumocóccica bacteriémica en adultos, dado que la información disponible en nuestro país deriva fundamentalmente de estudios en Pediatría ${ }^{7-10}$. La información sobre serotipos predominantes en la 
población adulta es más bien reciente y escasa, limitada a la Región de la Araucanía y Región Metropolitana ${ }^{11,12}$ y no incluye, necesariamente, aspectos de susceptibilidad in vitro a antimicrobianos y biología molecular.

El objetivo de este trabajo fue determinar la susceptibilidad antimicrobiana, serotipos y relación clonal de cepas de S. pneumoniae aisladas en episodios de bacteriemia de pacientes adultos atendidos en hospitales de la intercomuna Concepción- Talcahuano.

\section{Material y Métodos}

Se estudió 56 aislados de S. pneumoniae provenientes del torrente circulatorio, de igual número de pacientes sobre 15 años de edad, internados en el Hospital Clínico Regional de Concepción, Hospital Higueras de Talcahuano y Hospital Naval de Talcahuano durante el período enero 2005-agosto 2006. Se incluyó un aislado por paciente. Como controles se utilizaron las siguientes cepas:

- S. pneumoniae ATCC 49619 en los ensayos de susceptibilidad antimicrobiana.

- Enterococcus faecalis ATCC 29212 para evaluar el contenido adecuado de timidina en agar y caldo Mueller-Hinton.

- Clones internacionales Spain ${ }^{23 \mathrm{~F}}-1$, Spain $^{6 \mathrm{~B}}-2, \mathrm{Spain}^{9 \mathrm{~V}}-3$, Colombia ${ }^{5}-19$ y Colombia ${ }^{23 \mathrm{~F}}-26$ para la determinación de la relación clonal entre aislados.

Identificación y mantención de las cepas. La identificación se realizó de acuerdo a criterios fenotípicos y pruebas de susceptibilidad a optoquina, solubilidad en bilis $^{13}$ y kit comercial de aglutinación con partículas de látex Dryspot Pneumo Test ${ }^{\circledR}$ (Oxoid, Basingstoke, Reino Unido). Dos réplicas de cada cepa fueron mantenidas a $-80^{\circ} \mathrm{C}$ en el sistema de criotubos CryoBank ${ }^{\circledR}$ (Copan Diagnostics Inc., Corona, EE.UU.).

\section{Estudios de susceptibilidad antimicrobiana}

Determinación de patrones de resistencia. Se realizó por el método de difusión en agar, empleando oxacilina $(1 \mu \mathrm{g})$, eritromicina $(15 \mu \mathrm{g})$, trimetoprim/sulfametoxazol (cotrimoxazol) $(1,25 / 23,75 \mu \mathrm{g})$, tetraciclina $(30 \mu \mathrm{g})$, cloranfenicol $(30 \mu \mathrm{g})$, levofloxacina $(5 \mu \mathrm{g})$, moxifloxacina $(5 \mu \mathrm{g})$ y vancomicina $(30 \mu \mathrm{g})$, de acuerdo a las recomendaciones del Clinical and Laboratory Standards Institute (CLSI) ${ }^{14}$, utilizando como control la cepa de $S$. pneumoniae ATCC 49619.

Determinación del nivel de resistencia. En las cepas que presentaron resistencia mediante el método de difusión en agar, se determinó la concentración inhibitoria mínima (CIM) por el método de microdilución en caldo, según los criterios del CLSI ${ }^{15}$. Se utilizaron placas de microtitulación conteniendo penicilina G (Merck, Darmstadt, Alemania), cefotaxima (Sigma ${ }^{\circledR}$, Chemie GMBH Alemania), cloranfenicol (Calbiochem ${ }^{\circledR}$, Darmstadt, Alemania), tetraciclina (Calbiochem ${ }^{\circledR}$, Darmstadt, Alemania), trimetoprim (Sigma ${ }^{\circledR}$, Chemie GMBH, Alemania), sulfametoxazol (Sigma ${ }^{\circledR}$, Chemie GMBH Alemania) y eritromicina (Sigma ${ }^{\circledR}$, Chemie GMBH Alemania), en caldo Mueller-Hinton catión ajustado (Oxoid, Basingstoke, Reino Unido) suplementado con 3\% de sangre lisada de caballo. La cepa ATCC 49619 fue utilizada como control en los ensayos.

Serotipificación. Las cepas de S. pneumoniae fueron serotipificadas en el Instituto de Salud Pública mediante la reacción de Neufeld-Quellung, utilizando el kit Pneumotest $^{\circledR}$ (Staten Serum Institute, Copenhague, Dinamarca) ${ }^{16,17}$ compuesto por 12 antisueros polivalentes y 44 factores.

Tipificación molecular. La relación genética de los aislados de $S$. pneumoniae fue investigada por macrorestricción del ADN cromosómico mediante electroforesis en gel en campo pulsado (ECP) según el protocolo de Soares y cols ${ }^{18}$ y las modificaciones de Vela y cols ${ }^{19}$. En breve, los aislados fueron inoculados en $10 \mathrm{ml}$ de caldo Todd-Hewitt 3\% suplementado con extracto de levadura $(1 \%)$, glucosa ( $1 \%$ ) y glutamina $(22 \mathrm{mg} / \mathrm{ml})$, e incubados durante 6 horas a $37^{\circ} \mathrm{C}$. Las células fueron recuperadas por centrifugación, resuspendidas en PIV ( $\mathrm{NaCl}$-Tris $1 \mathrm{M}$ pH 8,0) y mezcladas con agarosa de bajo punto de fusión (Chromosomal Grade Agarose, Bio-Rad) al 1,5\% para inmovilizarlas en moldes adecuados. Los plugs fueron tratados con $5 \mu \mathrm{g} / \mathrm{ml}$ de ARNasa (MBI Fermentas), $1 \mathrm{mg} / \mathrm{ml}$ de proteinasa $\mathrm{K}$ (Invitrogen ${ }^{\circledR}$, Carisbad, CA) y posteriormente, digeridos con $30 \mathrm{U}$ de enzima SmaI (MBI Fermentas). Los fragmentos de restricción fueron separados en un sistema CHEF DRII ${ }^{\circledR}$ PFGE (Bio-Rad) en un gel de agarosa al 1\% (SeaKem ${ }^{\circledR}$ Gold Agarose) con pulso inicial de 1 segundo, pulso final de 30 segundos, voltaje de $6 \mathrm{~V} / \mathrm{cm}$ por 23 horas a $11,3^{\circ} \mathrm{C}$. Los geles fueron teñidos en una solución de bromuro de etidio $(0,7 \mu \mathrm{g} / \mathrm{ml})$, lavados en agua, visualizados en un transiluminador UV y capturados con el sistema fotográfico Kodak Digital Science 1D. Los patrones de restricción obtenidos fueron clasificados de acuerdo con los criterios de Tenover y cols ${ }^{20}$.

\section{Resultados}

De las 56 cepas de $S$. pneumoniae aisladas desde hemocultivos en pacientes adultos en el período de estudio, $59 \%$ provenían de pacientes entre 15 y 64 años de edad y el $41 \%$ restante correspondió a personas con edad igual o superior a 65 años. Treinta y dos por ciento de los aislados 


\begin{tabular}{|lccc|}
\hline \multicolumn{2}{|c|}{$\begin{array}{r}\text { Tabla 1. Concentración inhibitoria mínima en cepas de Streptococcus } \\
\text { pneumoniae resistentes por difusión en agar }\end{array}$} \\
\hline Agente antimicrobiano & $\begin{array}{c}\text { CIM }(\boldsymbol{\mu} \mathbf{g} / \mathbf{m l}) \\
\text { n de cepas } \\
\text { resistentes }\end{array}$ & Rango & $\begin{array}{c}\text { Media } \\
\text { geométrica }\end{array}$ \\
\hline Penicilina & 13 & $0,12-1$ & 0,44 \\
\hline Cefotaxima & 11 & $0,015-1$ & 0,37 \\
\hline Tetraciclina & 12 & $8-32$ & 12,7 \\
Cotrimoxazol & 10 & $4 / 76-8 / 152$ & $7,2 / 136,8$ \\
\hline Eritromicina & 10 & $2->2.048$ & 618,2 \\
\hline Cloranfenicol & 4 & 16 & 16 \\
\hline
\end{tabular}

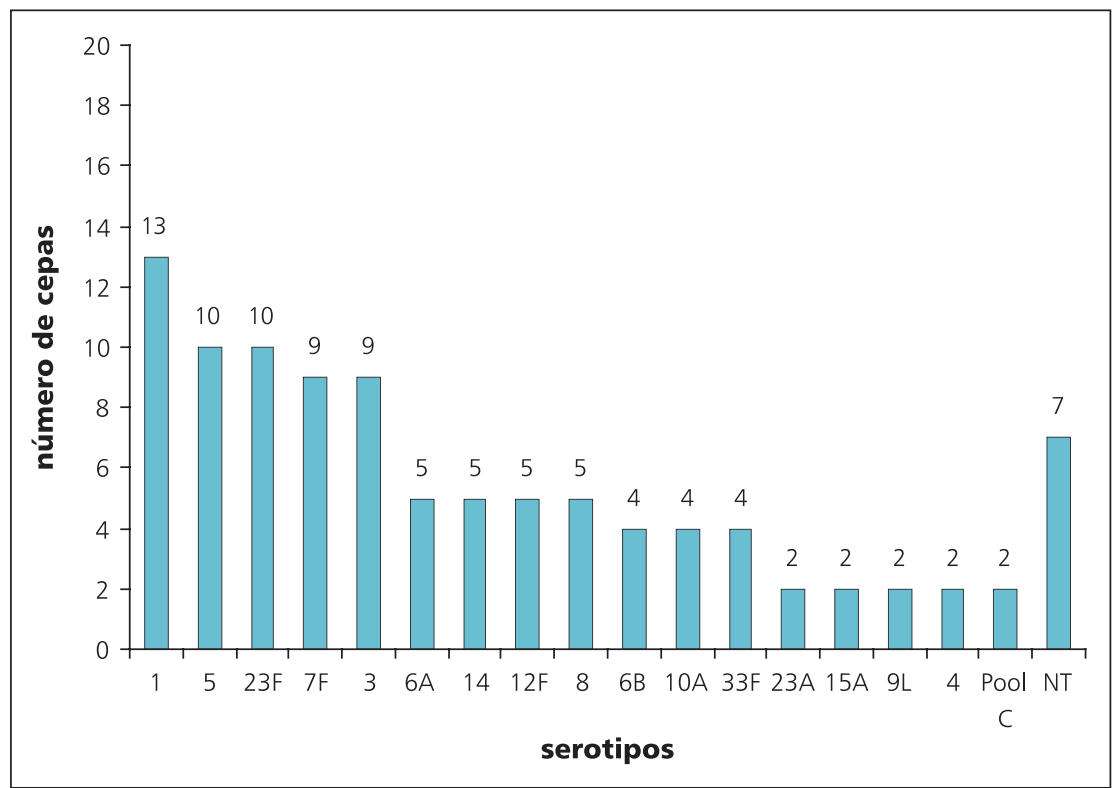

Figura 1. Distribución de serotipos capsulares de aislados de Streptococcus pneumoniae responsables de episodios bacteriémicos en población adulta de la intercomuna Concepción-Talcahuano. NT: no tipificable. provenían de pacientes de sexo femenino y $67,8 \%$ de varones. El diagnóstico clínico y, por lo tanto, la causa de hospitalización más frecuente en estos pacientes fue la neumonía (n: $51 ; 91,1 \%$ ), distribuyéndose los casos restantes en meningitis (n: $3 ; 5,3 \%)$, peritonitis (n: 1 ; $1,8 \%$ ) y absceso amigdalino (n: $1 ; 1,8 \%$ ).

Perfiles y niveles de resistencia. Al estudiar el comportamiento frente a los agentes antibacterianos, mediante el método de difusión en agar, se encontró que 13 cepas presentaron resistencia a penicilina; 10 cepas fueron resistentes y 9 presentaron susceptibilidad intermedia a cotrimoxazol; 12 cepas fueron resistentes a tetraciclina, 4 cepas a cloranfenicol y 10 cepas a eritromicina.

En las cepas no susceptibles por difusión en agar, se determinó el nivel de resistencia al antibacteriano correspondiente. Para el caso de los $\beta$-lactámicos, de las 13 cepas con un halo de inhibición de oxacilina $<19$ $\mathrm{mm}, 11$ de ellas presentaron susceptibilidad intermedia a penicilina (CIM 0,125 -1 $\mu \mathrm{g} / \mathrm{ml}$ ) y 2 fueron susceptibles a este antibacteriano $(\mathrm{CIM}<0,06 \mu \mathrm{g} / \mathrm{ml}$ ) de acuerdo a la antigua recomendación del CLSI. ${ }^{15}$ Sin embargo, según los nuevos criterios del CLSI ${ }^{21}$, todos los aislados extra-meníngeos fueron susceptibles a penicilina (nuevo criterio de susceptibilidad CLSI foco extrameníngeo, CIM $\leq 2 \mu \mathrm{g} / \mathrm{ml}$ ). De los 3 aislados meníngeos, 1 fue resistente $(\mathrm{CIM}=0,12 \mu \mathrm{g} / \mathrm{ml}$, nuevo criterio de resistencia CLSI foco meníngeo $\geq 0,12 \mu \mathrm{g} / \mathrm{ml})^{21}$. Además, la totalidad de las cepas fue susceptible a cefotaxima (Tabla 1). Con respecto a los otros agentes antibacterianos, $18 \%$ de las cepas ensayadas presentó resistencia frente a cotrimoxazol; $21,4 \%$ a tetraciclina; $7,1 \%$ a cloranfenicol y $18 \%$ presentó resistencia a eritromicina. No se detectaron cepas resistentes a levofloxacina, moxifloxacina ni vancomicina.

Serotipificación. La serotipificación capsular demostró una variedad importante de tipos capsulares, con los
Figura 2. Patrones de restricción de ADN cromosomal por electroforesis en campo pulsante de aislados de Streptococcus pneumoniae de procesos bacteriémicos en pacientes adultos. $\lambda$ : lambda ladder.

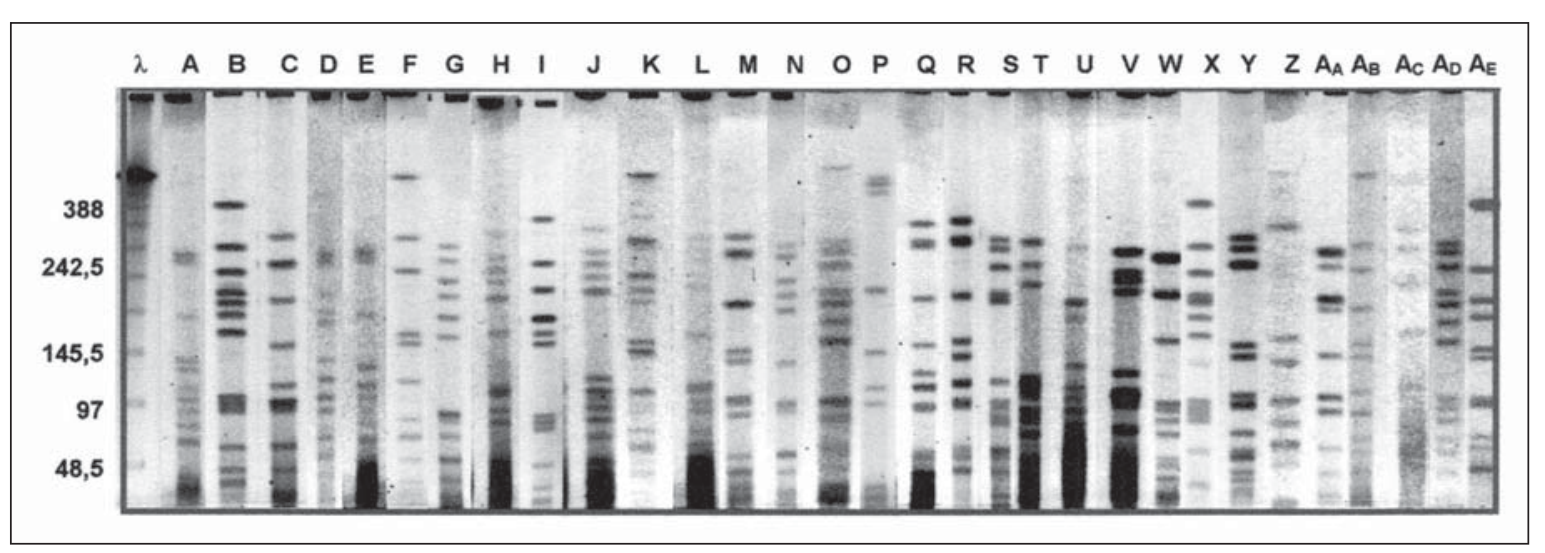


Tabla 2. Distribución de patrones de restricción de ADN cromosómico y serotipos de aislados de

S. pneumoniae de procesos bacteriémicos en adultos

\begin{tabular}{|c|c|}
\hline Patrón & Serotipo ( $n^{\circ}$ cepas) \\
\hline A & $33 F(1)$ \\
\hline B & $23 F(1)$ \\
\hline C & $23 F(1)$ \\
\hline D & $6 \mathrm{~A}(1)$ \\
\hline E & $6 \mathrm{~A}(1)$ \\
\hline $\mathrm{F}$ & $7 F(1)$ \\
\hline G & $14(2)$ \\
\hline $\mathrm{H}$ & $7 F(2)$ \\
\hline । & $23 F(2)$ \\
\hline J & $7 F(2)$ \\
\hline K & $1(1)$ \\
\hline L & $33 F(1)$ \\
\hline M & $14(1)$ \\
\hline $\mathrm{N}$ & $3(3)-N T(1)$ \\
\hline $\mathrm{O}$ & $1(1)$ \\
\hline$P$ & $8(1)-N T(1)$ \\
\hline Q & $3(1)-8(1)-10 A(1)$ \\
\hline$R$ & $6 B(1)$ \\
\hline S & $8(1)-N T(1)$ \\
\hline T & $12 F(3)$ \\
\hline U & $15 A(1)$ \\
\hline v & $6 \mathrm{~A}(1)$ \\
\hline W & $1(1)-5(6)$ \\
\hline$x$ & $23 F(1)$ \\
\hline Y & $1(1)$ \\
\hline Z & $10 \mathrm{~A}(1)$ \\
\hline$A_{A}$ & $6 \mathrm{~B}(1)$ \\
\hline$A_{B}$ & $23 F(1)$ \\
\hline$A_{c}$ & NT (1) \\
\hline$A_{D}$ & $1(2)$ \\
\hline$A_{E}$ & 15A (1) Pool C (1) \\
\hline
\end{tabular}

serotipos 1, 5, 23F, 7F y 3 como prevalentes en las cepas estudiadas. Así, 52\% (29/56) de los aislados analizados presentaron como antígeno capsular uno de estos cinco serotipos. El 48\% restante expresó serotipos capsulares que se presentaron en una frecuencia menor a $5,4 \%$ (serotipos 6A, 14, 12F, 8, 6B, 10A, 33F, 23A, 15A, 9L, 4 y pool C) y sólo 7 cepas fueron definidas como no tipificables (Figura 1).
Tipificación molecular. Con los ensayos de tipificación molecular por ECP fue posible analizar 52 de los 56 aislados de $S$. pneumoniae, encontrándose 31 patrones electroforéticos diferentes y 12 grupos clonales (G-J, $\mathrm{N}, \mathrm{P}, \mathrm{Q}, \mathrm{S}, \mathrm{T} \mathrm{W}, \mathrm{A}_{\mathrm{D}} \mathrm{y} \mathrm{A}_{\mathrm{E}}$ ), cada grupo constituido por 2-7 aislados con patrones de restricción genéticamente relacionados o idénticos (Figura 2 y Tabla 2). Se descartó la presencia de un componente clonal predominante. Se evidenció relación entre serotipo capsular y clonalidad al encontrar aislados genéticamente relacionados, cercanamente relacionados $\mathrm{y}$, en algunas ocasiones, posiblemente relacionados, en cepas de un determinado serotipo (cepas serotipos 23F, 7F, 14, 3, 1, 5 y 12F).

\section{Discusión}

En general en nuestro país, los estudios de vigilancia, con los antiguos puntos de corte del CLSI, reportaron valores de resistencia a penicilina que variaban entre 20 y $30 \%$, con significativas variaciones regionales ${ }^{22,23}$. Por otra parte, se ha demostrado una evidente diferencia de susceptibilidad entre los aislados de la población pediátrica en comparación con la adulta $(15,1 \text { a 7,3\% })^{24}$.

Existe poca información nacional sobre susceptibilidad in vitro, serotipificación y relación clonal de aislados de $S$. pneumoniae obtenidos del torrente circulatorio de población adulta.

En este estudio fue posible determinar que los aislados estudiados mantienen aún una importante susceptibilidad a penicilina, incluso utilizando los antiguos puntos de corte del CLSI (80,4\% de susceptibilidad y $19,6 \%$ de cepas con susceptibilidad intermedia) y cefotaxima (100\% de cepas susceptibles); según la última recomendación del CLSI, sólo un aislado de foco meníngeo fue resistente a penicilina ${ }^{25}$. Con respecto a otros antimicrobianos estudiados, se encontró resistencia particularmente a macrólidos, tetraciclina y cotrimoxazol.

La variedad de polisacáridos capsulares fue importante; sin embargo, se destaca un claro predominio de los serotipos 1, 5, 23F, 7F y 3, con frecuencia sobre $50 \%$, comparado con los restantes serotipos $(<5,4 \%)$. La fórmula de la vacuna polisacárida que incluye los 23 polisacáridos capsulares que con mayor frecuencia se asocian con enfermedades invasoras en América del Norte $(1,2,3,4,5,6 \mathrm{~B}, 7 \mathrm{~F}, 8,9 \mathrm{~N}, 9 \mathrm{~V}, 10 \mathrm{~A}, 11 \mathrm{~A}, 12 \mathrm{~F}, 14,15 \mathrm{~B}$, $17 \mathrm{~F}, 18 \mathrm{C}, 19 \mathrm{~A}, 19 \mathrm{~F}, 20,22 \mathrm{~F}, 23 \mathrm{~F}$ y $33 \mathrm{~F}$ ), presentaría una cobertura teórica de $82 \%$ de las cepas de $S$. pneumoniae aisladas en nuestro estudio. Este porcentaje podría ser mayor al tener presente el concepto de protección cruzada, que deriva de la similitud antigénica de los polisacáridos capsulares de aislados pertenecientes al mismo serogrupo. La inmunización con el serotipo 6B puede conferir protección frente al serotipo $6 \mathrm{~A}$ presente en tres cepas clínicas 
en nuestro estudio, pero ausente de la formulación de la vacuna. Situación similar podría producirse con el serotipo $23 \mathrm{~F}$ y los serotipos $9 \mathrm{~V}, 9 \mathrm{~N}, 15 \mathrm{~B}$, entregando un efecto protector frente al serotipo $23 \mathrm{~A}$ y serotipos $9 \mathrm{~L}$ y $15 \mathrm{~A}$, respectivamente. Con esto, teóricamente, la cobertura en términos del nivel de protección inmunológica entregada, podría alcanzar valores cercanos a $90 \%$.

Respecto de lo anterior, y de manera reciente, se ha propuesto un método para la determinación de serotipos y serogrupos capsulares en cepas de $S$. pneumoniae, que combina la amplificación del locus capsular completo y la posterior digestión de ese amplicón logrando patrones de restricción serotipo-específico (RCP-RFLP) y generando una base de datos que permitiría, de manera simplificada, lograr un mayor poder discriminatorio en la identificación ${ }^{26}$.

El estudio de relación genética mediante ensayos ECP revela una gran diversidad clonal en las cepas de $S$. pneumoniae investigadas, sin un componente clonal prevalente, como tampoco relación con clones internacionales circulantes en países sudamericanos y descritos en pacientes pediátricos (Spain ${ }^{23 \mathrm{~F}}-1$, Spain $^{6 \mathrm{~B}}-2$, Spain ${ }^{9 \mathrm{~V}}-3$, Colombia $^{5}-19$ y Colombia $\left.{ }^{23 \mathrm{~F}}-26\right)^{6,10,19,27-30}$.

Además, se evidenció la relación entre serotipo capsular y clonalidad, al determinar la presencia, en cepas con un determinado polisacárido capsular, de aislados genéticamente relacionados, cercanamente relacionadas $\mathrm{y}$, en algunas ocasiones, posiblemente relacionados (cepas serotipo 23F, 7F, 14, 3, 1, 5 y 12F).

En resumen, nuestro estudio confirma la susceptibilidad a penicilina de cepas aisladas del torrente circulatorio de población adulta de la intercomuna ConcepciónTalcahuano, de acuerdo a cualquiera de los puntos de corte propuestos por el CLSI. De hecho, si se utilizan los puntos de cortes propuestos por el Drug Resistant Streptococcus pneumoniae Therapeutic Group ${ }^{31}$ y los nuevos puntos de corte del CLSI, habría sólo un aislado - procedente de foco meníngeo- resistente a penicilina. Por otra parte, se demuestra la ausencia de un clon predominante y de un serotipo en particular, incluidos aquellos de amplia distribución geográfica.

Finalmente, debe destacarse que el número de aislados representa sobre $90 \%$ de los aislados del torrente circula- torio recolectados anualmente en los hospitales Clínico Regional de Concepción y Naval de Talcahuano, lo que asociado al diseño descriptivo y el período estudiado (enero 2005-agosto 2006) hace metodológicamente imposible establecer comparaciones sobre endemicidad y enfermedad serotipo-específica como la estudiada en pediatría ${ }^{32}$. A pesar de lo anterior, destaca la amplia variabilidad de serotipos identificados y patrones electroforéticos encontrados, con ausencia de clones epidémicos y la evidente susceptibilidad a penicilina con cualquiera de los puntos de corte establecidos, información que nuestro grupo ha sido enfático en propiciar y utilizar ${ }^{33,34}$.

Agradecimientos: A los profesionales de los Laboratorios de Microbiología, Angelo Cabezas (Hospital Naval), Pamela Rojas y Alejandra Soto (Hospital Higueras) y Nancy Henríquez (Hospital Guillermo Grant Benavente) por proporcionar las cepas empleadas en este estudio.

\section{Resumen}

Las infecciones ocasionadas por Streptococcus pneumoniae constituyen un problema de salud pública. En nuestro país existe escasa información sobre aislados de procesos bacteriémicos en población adulta. Se estudió la susceptibilidad, serotipos y relación clonal de 56 aislados de $S$. pneumoniae desde hemocultivos, entre enero 2005 y agosto 2006, de pacientes adultos de la intercomuna Concepción-Talcahuano, Región del Bío-Bío, Chile. Se encontró resistencia a tetraciclina $(21,4 \%)$, cotrimoxazol $(18 \%)$, eritromicina (18\%), cloranfenicol $(7 \%)$ y a penicilina en un solo aislado procedente de un foco meníngeo (2\%). La totalidad mostró susceptibilidad a cefotaxima, levofloxacina, moxifloxacina y vancomicina. Se demostró una amplia variedad de serotipos capsulares, con predominio de los serotipos 1, 5, 23F, 7F y 3. El análisis de macrorestricción y electroforesis en campo pulsado reveló 31 patrones electroforéticos con 12 grupos clonales, descartando un clon predominante. De acuerdo a los resultados, al menos $80 \%$ de los serotipos de aislados de S. pneumoniae de procesos bacteriémicos están incluidos en la vacuna comercial disponible.

\section{Referencias}

1.- Musher D M. Infections caused by Streptococcus pneumoniae: clinical spectrum, pathogenesis, immunity, and treatment. Clin Infect Dis 1992; 14: 801-9.

2.- Giebink G S. The prevention of pneumococcal disease in children. N Engl J Med. 2001; 345: 1177-83.

3.- Trampuz A, Widmer AF, Fluckiger U,
Haenggi M, Frei R, Zimmerli W. Changes in the epidemiology of pneumococcal bacteremia in a Swiss university hospital during a 15-year period, 1986-2000. Mayo Clin Proc 2004; 79 : 604-12.

4.- Musher D M. Streptococcus pneumoniae. Mandell G L, Bennett J E, Dolin R, editors. Mandell, Douglas and Bennett's Principles and Practice of Infectious Diseases, Seven ${ }^{\text {th }}$ ed. Philadelphia: Churchill Livingstone Elsevier;
2010; p. 2623-42.

5.- Feldman Ch. Clinical relevance of antimicrobial resistance in the management of pneumococcal community-acquired pneumonia. J Lab Clin Med 2004; 143: 269-83.

6.- Castañeda E, Tomasz A, Vela M. Penicillinresistant Streptococcus pneumoniae in Colombia: presence of international epidemic clones. Microb Drug Resist 1998; 4: 233-9. 
7.- Lagos R, Muñoz A, Valenzuela M T, Heitmann I, Levine M M. Population-based surveillance for hospitalized and ambulatory pediatric invasive pneumococcal disease in Santiago, Chile. Pediatr Infect Dis J 2002; 21: 1115-23.

8.- Levine M M, Lagos R, Levine OS, Heitmann I, Enríquez N, Pinto M E, et al. Epidemiology of invasive pneumococcal infections in infants and young children in Metropolitan Santiago, Chile, a newly industrializing country. Pediatr Infect Dis J 1998; 17: 287-93.

9.- Contreras L, Fica A, Figueroa O, Enríquez N, Urrutia P, Herrera P. Resistencia de Streptococcus pneumoniae a penicilina y su asociación con factores clínicos y epidemiológicos. Rev Méd Chile 2002; 130: 26-34.

10.- Di Fabio J L, Castañeda E, Agudelo C I, De La Hoz F, Hortal M, Camou T, et al. Evolution of Streptococcus pneumoniae serotypes and penicillin susceptibility in Latin America, Sireva-Vigía Group, 1993 to 1999. PAHO Sireva-Vigía Study Group. Pan American Health Organization. Pediatr Infect Dis J 2001; 20: 959-67.

11.- Inostroza J, Illesca V, Reydet P, Vinet A M, Ossa G, Muñoz S et al. Ten-year surveillance of pneumococcal infections in Temuco, Chile: implications for vaccination strategies. Clin Vaccine Immunol 2007; 14: 660-4.

12.- Maldonado A, Seoane M, San Martín O, Hormazábal J C, Lagos R. Evaluación retrospectiva de la vigilancia de Streptococcus pneumoniae causante de enfermedades invasoras en adultos de la Región Metropolitana-Chile: 2000-2006. Rev Chil Infect 2007; 24: 446-52.

13.- Perilla M J, Ajello G, Bopp C, Elliot J, Facklam R, Knapp J S, et al. Manual de Laboratorio para la identificación y prueba de susceptibilidad a los antimicrobianos de patógenos bacterianos de importancia para la Salud Pública en el mundo en desarrollo. Haemophilus influenzae, Neisseria meningitidis, Streptococcus pneumoniae, Neisseria gonorrhoeae, Salmonella serotipo Typhi y Vibrio cholerae. Centros para el Control y la Prevención de Enfermedades. Centros para el Control y la Prevención de Enfermedades, Atlanta, Georgia, EUA.2004, p. 49-67.

14.- Clinical and Laboratory Standards Institute. 2006. Performance standards for antimicrobial disk susceptibility test; Approved standardsNinth Edition M2-A9, CLSI, Wayne, Pa.
15.- Clinical and Laboratory Standards Institute. 2006. Methods for dilution antimicrobial susceptibility test for bacteria that grow aerobically; Approved standards-Seventh Edition M7-A7, CLSI, Wayne, Pa.

16.- Sorensen RU. Typing pneumococci by using 12 pooled antisera. J Clin Microbiol 1993; 31: 2097-100.

17.- Lalitha M, Thomas K, Kumar R, Steinhoff M. Serotyping of Streptococcus pneumoniae by coagglutination with 12 pooled antisera. J Clin Microbiol 1999; 37: 263-5.

18.- Soares S, Kristinsson K, Musser J, Tomasz A. Evidence for the introduction of a multiresistant clone of serotype 6B Streptococcus pneumoniae from Spain to Iceland in the late 1980's. J Infect Dis 1993; 168: 158-63.

19.- Vela M, Fonseca N, Di Fabio J, Castañeda E. Presence of international multiresistant clones of Streptococcus pneumoniae in Colombia. Microb Drug Resist 2001; 7: 153-64.

20.- Tenover F, Arbeit R, Goering R, Mickelsen P, Murray B, Persing D, et al. Interpreting chromosomal DNA restriction patterns produced by pulse-field gel electrophoresis: criteria for bacterial strain typing. J Clin Microb 1995; 33: 2233-9.

21.- Clinical and Laboratory Standards Institute Performance. 2008. Standards for antimicrobial susceptibility testing:18th informational supplement. CLSI document M100-S18. Wayne, PA.

22.- Díaz A, Torres C, Flores L, García P, Saldías F. Neumonía neumocócica adquirida en la comunidad en pacientes adultos hospitalizados. Rev Méd Chile 2003; 131: 505-14.

23.- Soler T, Salamanca L, Arbo G, Molina E. Estudio de sensibilidad in vitro de Streptococcus pneumoniae de infecciones respiratorias bajas en el Instituto Nacional de Tórax (INT). Rev Méd Chile 2002; 130: 304-8.

24.- Saldías F, Flores L, Torres MC, García P, Díaz A. Susceptibilidad a antimicrobianos de Streptococcus pneumoniae en población infantil y adulta de Santiago. Período 1997-2003. Rev Méd Chile 2005; 133: 42-9.

25.- Weinstein M, Klugman K, Jones R. Rationale for revised penicillin susceptibility breakpoints versus Streptococcus pneumoniae: coping with antimicrobial susceptibility in an era of resistance. Clin Infect Dis. 2009; 48: 1596-600

26.- Batt S, Charalambus B, Mc Hugh T, Martin S, Gillespie S. Novel PCR-restriction fragment length polymorphism method for determining serotypes or serogroups of Streptococcus pneumoniae isolates. J Clin Microbiol 2005; 43: 2656-61.

27.- Camou T, Hortal M, Tomasz A. The apparent importation of penicillin-resistant capsular type 14 Spanish/French clone of Streptococcus pneumoniae into Uruguay in the early 1990s. Microb Drug Resist 1998; 4: 219-24.

28.- Echániz-Aviles G, Velásquez-Meza M E, Carnalla-Barajas M N, Soto-Noguerón A, Di Fabio J, Solórzano-Santos F, et al. Predominance of the multiresistant 23F international clone of Streptococcus pneumoniae among isolates from Mexico. Microb Drug Resist 1998; 4: 241-6.

29.- Tamayo M, Sa-Leao R, Santos Sánchez I, Castañeda E, de Lancastre H. Dissemination of a chloramphenicol-and tetracycline-resistant but penicillin-susceptible invasive clone of serotype 5 Streptococcus pneumoniae in Colombia. J Clin Microbiol 1999; 37: 2337-42.

30.- Wolf B, Rey L, Brisse S, Moreira L, Milatovic D, Fleer A, et al. Molecular epidemiology of penicillin-resistant Streptococcus pneumoniae colonizing children with community-acquired pneumonia and children attending day-care centres in Fortaleza, Brazil. J Antimicrob Chemother 2000; 46: 757-65.

31.- Heffelfinger J D, Dowell S F, Jorgensen J H, Klugman K P, Mabry L R, Musher D M, et al; and "the Drug-Resistant S. pneumoniae Therapeutic Working Group": Management of community-acquired pneumonia in the era of pneumococcal resistance: A report from the Drug Resistant Streptococcus pneumoniae Penicillin Therapeutic Working Group. Arch Intern Med 2000; 160: 1399-408.

32.- Lagos R, Muñoz A, San Martín O, Maldonado A, Hormazabal J C, Blackwelder W C, et al. Age-and serotypespecific pediatric invasive pneumococcal disease: insights from systematic surveillance in Santiago, Chile, 1994-2007. J Infect Dis 2008; 198: 1809-17.

33.- Mella S, Blamey R, Paiva O, Yáñez J, Riedel G, Aylwin M, et al. Impacto de la evaluación infectológica en el uso racional de antimicrobianos en pacientes con bacteriemia por Streptococcus pneumoniae. Rev Chil Infect 2007; 24: 264-269.

34.- Mella S, Muñoz M. Utilidad de penicilina G en infecciones estreptocócicas. Rev Méd Chile 2009; 137: 585-6. 